\title{
Survival in critically ill admissions with and without COVID-19 at an academic medical center during the height of the pandemic
}

\author{
Caroline A. Ricard ${ }^{* 1}$, Janelle O. Poyant ${ }^{2}$, Sharon L. Holewinski ${ }^{3}$, Stanley A. Nasraway $\mathrm{Jr}^{4}$ \\ ${ }^{1}$ Department of Surgery, Tufts Medical Center, Boston, MA, United States \\ ${ }^{2}$ Department of Pharmacy, Tufts Medical Center, Boston, MA, United States \\ ${ }^{3}$ Division of Trauma \& Acute Care Surgery, Tufts Medical Center, Boston, MA, United States \\ ${ }^{4}$ Department of Surgery, Tufts Medical Center, Tufts University School of Medicine, Boston, MA, United States
}

Received: February 22, 2021

Accepted: March 15, 2021

Online Published: April 14, 2021

DOI: $10.5430 /$ jha.v10n2p29

URL: https://doi.org/10.5430/jha.v10n2p29

\begin{abstract}
Objective: Early reports demonstrate that patients with Severe Acute Respiratory Syndrome Coronavirus-2 (SARS-CoV-2) infection have high rates of hospitalization, intensive care unit (ICU) admission, and death. We sought to examine characteristics of ICU admissions with and without Coronavirus 2019 (COVID-19) and to compare outcomes between these two critically ill cohorts.

Methods: A retrospective analysis of 600 unique adult ICU admissions was conducted at an academic medical center in Boston, MA from March 22 to May 31, 2020.

Results: Of 600 ICU admissions, 170 (28.3\%) tested positive for COVID-19. Those with COVID-19 had greater severity of illness and were more likely to require mechanical ventilation (MV). Hospital and ICU mortality rates were greater in the COVID-19 group ( $22.4 \%$ vs. $9.5 \%$; $18.2 \%$ vs. $7.2 \%$, respectively), but lower than previous reports. Unadjusted odds ratio (OR) for COVID-19 as a predictor of hospital mortality was 2.73 (95\% CI 1.68 to 4.43 ), but when accounting for clinical characteristics and severity of illness, adjusted OR for hospital mortality was no different (1.09 [95\% CI 0.50 to 2.41]) among those with and without COVID-19.

Conclusions: COVID-19 admissions had greater severity of illness and suffered higher crude mortality rates compared to the non-COVID-19 cohort. However, there was no significant difference in the adjusted OR for hospital mortality between patients with and without COVID-19. This novel finding may be attributed to the "learning curve" from other healthcare system experiences, early hospital-wide preparation, and dedicated intensive care.
\end{abstract}

Key Words: Coronavirus infections, COVID-19, Pandemics, Critical care, Delivery of health care, Intensive care units, Critical care outcomes

\section{INTRODUCTION}

Coronavirus 2019 (COVID-19) at the time of this writing has infected nearly 28 million and killed nearly a half of a million people in the United States. Projected estimates of this pandemic include more than 600,000 cumulative deaths and upwards of $\$ 16$ trillion in total cost. ${ }^{[1]}$ Massachusetts

*Correspondence: Caroline A. Ricard; Email: cricard@tuftsmedicalcenter.org; Address: 800 Washington St, Boston, MA, 02116, United States. 
was struck in the spring of 2020 and has had the third highest mortality rate $(120$ per 100,000$)$ among the 50 states. $^{[2]}$

Early COVID-19 reports demonstrate that patients with Severe Acute Respiratory Syndrome Coronavirus-2 (SARS$\mathrm{CoV}-2$ ) infection have high rates of hospitalization, intensive care unit (ICU) admission, and death. ${ }^{[3-13]}$ Herein, we sought to examine factors associated with mortality and resource utilization among ICU admissions with and without COVID19 from March 22 to May 31, 2020 at the height of the first pandemic surge. We hypothesized that severity of illness, artificial life supports, and outcomes between these two critically ill cohorts would differ.

\section{MethodS}

\subsection{Setting, study population, and design}

The setting of this analysis is a 415-bed level I trauma, tertiary-care academic medical center in Boston, MA normally staffed with five adult ICUs: Surgical, Cardiothoracic, Medical, Cardiac, and Neurosciences. During the pandemic, additional adult COVID-19 ICU beds were developed by utilizing the Pediatric ICU, expanding an intermediate care unit, and by converting a large medical-surgical ward and part of the Post Anesthesia Care Unit to ICU-level care under the governor's emergency declaration. A concerted effort was made by the hospital to decant the inpatient units and ICUs and to eliminate elective admissions so as to gain ICU bed capacity prior to pandemic escalation. This two-week pre-pandemic period was also used to recruit staff, redesign house staff and attending staffing models, train healthcare workers on the use of personal protective equipment (PPE), refine proning techniques through repeated simulation, and establish triage priorities and redistribution of staff. As an example, operating rooms were much reduced in use; therefore, operating room nurses and some surgeons were reassigned to the ICUs to manage PPE and to closely observe proper donning and doffing by ICU staff. A rapid innovation working group was established to develop new approaches and treatments, including original techniques for bedside tracheostomy and percutaneous endoscopic gastrostomy tube placements in highly contagious patients with COVID-19. ${ }^{[14]}$

This retrospective observational analysis collected and analyzed de-identified patient data using the MDN Phoenix database (Medical Decisions Network; Charlottesville, VA) Data collected within the Phoenix database were based on the number of ICU admissions for both COVID-19 and nonCOVID-19 patients. There were 574 unique patients, 600 unique ICU admissions, and 722 ICU encounters during the study interval included in our analysis. A unique ICU admission was counted each time a patient required escalation to ICU level care. An ICU encounter was defined as a unique
ICU admission or an ICU to ICU transfer, which happened regularly to balance the census between ICUs. Unique admissions were selected as the study denominator, as this metric most accurately captured the population's burden of illness throughout the study period.

Demographic characteristics, comorbidities, and ICU resources were recorded, including use of corticosteroids, proning, mechanical ventilation (MV), renal replacement therapy (RRT), and extracorporeal membrane oxygenation (ECMO). The Acute Physiology and Chronic Health Evaluation (APACHE) II and IV scoring systems were used to quantify severity of illness within the first 24 hours of ICU admission. ${ }^{[16,17]}$ Calculated metrics including standardized mortality and length of stay (LOS) ratios (observed/expected $[\mathrm{O} / \mathrm{E}]$ ) were based on the ACUITY2019 score, an internally validated scoring system constructed using a contemporary database that adjusts for severity of patient case mix, providing predicted outcomes that allow for comparative assessments of performance (personal communication: Andrew Kramer, PhD). ACUITY2019 is the successor to ACUITY2016 and differs from its predecessor in removing the requirement for manual data elements, using real time admission data, and replacing APACHE-derived reason for ICU admission with diagnosis-related group codes. All of the patients included in this study have completed outcomes; they either died in hospital or were discharged. Additionally, we reviewed the most important COVID-19 published studies with outcomes. We aimed to compare ICU and hospital mortality rates at this hospital with those published during the same relative time period.

\subsection{Statistical analysis}

Data were summarized as means and standard deviations, medians and 25th to 75th percentiles, or numbers and percentages for COVID-19 and non-COVID-19 admissions. Differences between COVID-19 and non-COVID-19 admissions were also computed together with $95 \%$ confidence intervals (CI) for the differences. Estimates of unadjusted and adjusted odds ratios (OR) and 95\% CI for COVID-19 as associated with hospital mortality were computed using logistic regression models. We also used logistic regression to estimate OR and $95 \%$ CI for comparisons of hospital and ICU mortality at this hospital with performance at other healthcare settings based on published data. All analyses were done using SAS software (version 9.4 through SAS Enterprise Guide version 8.2 Copyright (C) 2019, SAS Institute Inc., Cary, NC, USA). This study was approved by the Institutional Review Board: informed consent for de-identified data was waived. The manuscript was created in accordance with the STROBE equator guidelines for observational studies. 


\section{RESULTS}

Of the 600 ICU admissions, 170 (28.3\%) tested positive for SARS-CoV-2 (see Table 1). Aside from a higher prevalence of Hispanics among the COVID-19 cohort, there was no difference in races between those with and without COVID19. Admissions with COVID-19 were more likely to have comorbidities including diabetes mellitus, hypertension, and chronic kidney disease. Those with COVID-19 had higher severity of illness and were more frequently admitted as transfers from outside hospitals (OSH). The COVID-19 cohort required more frequent escalation to and longer duration of MV and RRT (see Table 2).

Table 1. Demographic characteristics, comorbidities, and resources of ICU admissions between 3/22/20 - 5/31/20

\begin{tabular}{|c|c|c|c|c|c|c|}
\hline & $\begin{array}{l}\text { COVID-19 } \\
\text { Admissions } \\
(\mathrm{n}=170)\end{array}$ & $\begin{array}{l}\text { Non-COVID-19 } \\
\text { Admissions } \\
(\mathrm{n}=\mathbf{4 3 0})\end{array}$ & $\begin{array}{l}\text { [COVID-19 minus } \\
\text { Non-COVID-19] } \\
\text { Difference (95\% CI) }\end{array}$ & $\begin{array}{l}\text { COVID-19 } \\
\text { Admissions on } \\
\text { MV }(\mathbf{n}=119)\end{array}$ & $\begin{array}{l}\text { Non-COVID-19 } \\
\text { Admissions on } \\
\text { MV }(n=118)\end{array}$ & $\begin{array}{l}\text { [COVID-19 on MV minus } \\
\text { Non-COVID-19 on MV] } \\
\text { Difference }(95 \% \mathrm{CI})\end{array}$ \\
\hline Female & $63(37.1)$ & $178(41.4)$ & $-4.3(-13$ to 4.3$)$ & $43(36.1)$ & $40(33.9)$ & $2.2(-9.9$ to 14.4$)$ \\
\hline Age, years & $60.6 \pm 17.1$ & $60.8 \pm 17.6$ & $-0.2(-3.3$ to 2.9$)$ & $61.1 \pm 15.7$ & $59.8 \pm 17.2$ & $1.3(-2.9$ to 5.5$)$ \\
\hline \multicolumn{7}{|l|}{ Race } \\
\hline White & $85(50)$ & $289(67.2)$ & $-17.2(-26$ to -8.5$)$ & $61(51.3)$ & $86(72.9)$ & $-21.6(-34$ to -9.6$)$ \\
\hline Black & $26(15.3)$ & $55(12.8)$ & $2.5(-3.8$ to 8.8$)$ & $18(15.1)$ & $8(6.8)$ & $8.3(0.5$ to 16.2$)$ \\
\hline Hispanic & $27(15.9)$ & $20(4.7)$ & $11.2(5.4$ to 17.1$)$ & $19(16)$ & $8(6.8)$ & $9.2(1.2$ to 17.2$)$ \\
\hline Asian & $25(14.7)$ & $39(9.1)$ & $5.6(-0.3$ to 11.6$)$ & $16(13.4)$ & $8(6.8)$ & $6.7(-1$ to 14.3$)$ \\
\hline OTH/UNK & $7(4.1)$ & $27(6.3)$ & $-2.2(-5.9$ to 1.6$)$ & $5(4.2)$ & $8(6.8)$ & $-2.6(-8.4$ to 3.2$)$ \\
\hline \multicolumn{7}{|l|}{ Admission origin } \\
\hline OR & $7(4.1)$ & $92(21.5)$ & $-17.4(-22$ to -12.4$)$ & $3(2.5)$ & $24(20.5)$ & $-18(-26$ to -10.2$)$ \\
\hline Floor & $30(17.8)$ & $50(11.7)$ & $6.1(-0.4$ to 12.6$)$ & $18(15.1)$ & $10(8.5)$ & $6.6(-1.6$ to 14.8$)$ \\
\hline $\mathrm{ED}$ & 37 (21.9) & $175(40.9)$ & $-19(-27$ to -11.2$)$ & $16(13.4)$ & $41(35)$ & $-21.6(-32$ to -11$)$ \\
\hline OSH & $95(56.2)$ & $102(23.8)$ & 32.4 (24 to 40.9$)$ & $82(68.9)$ & $36(30.8)$ & 38.1 (26 to 49.9$)$ \\
\hline Our ICU & $\begin{array}{l}0(0) \\
(\mathrm{n}=169)\end{array}$ & $\begin{array}{l}4(0.9) \\
(n=428)\end{array}$ & $-0.9(-1.8$ to 0$)$ & $0(0)$ & $\begin{array}{l}4(3.4) \\
(n=117)\end{array}$ & $-3.4(-6.7$ to -0.1$)$ \\
\hline $\begin{array}{l}\text { Mean daily } \\
\text { admissions }\end{array}$ & 7.85 & 2.16 & - & 1.49 & 1.67 & - \\
\hline APACHE II ${ }^{\mathrm{a}}$ & $\begin{array}{l}23[15-28] \\
(\mathrm{n}=104)\end{array}$ & $\begin{array}{l}15[10-20] \\
(\mathrm{n}=205)\end{array}$ & $8(5.1$ to 10.9$)$ & $\begin{array}{l}26.5[21-30] \\
(n=74)\end{array}$ & $\begin{array}{l}21[16-28] \\
(\mathrm{n}=64)\end{array}$ & $5(1.3$ to 8.7$)$ \\
\hline APACHE IV & $\begin{array}{l}82.5[54.5-103.3] \\
(n=104)\end{array}$ & $\begin{array}{l}50[38-67] \\
(\mathrm{n}=205)\end{array}$ & $32(21.2$ to 42.8$)$ & $\begin{array}{l}94.5[75-108] \\
(\mathrm{n}=74)\end{array}$ & $\begin{array}{l}69.5[53.5-98] \\
(n=64)\end{array}$ & 23 (9.6 to 36.4 ) \\
\hline $\mathrm{BMI}>30, \mathrm{mg} / \mathrm{m}^{2}$ & $41(24.1)$ & $80(18.6)$ & $5.5(-1.9$ to 12.9$)$ & $36(30.3)$ & $27(22.9)$ & $7.4(-3.8$ to 18.6$)$ \\
\hline \multicolumn{7}{|l|}{ Comorbidities } \\
\hline $\mathrm{DM}$ & $71(41.8)$ & $131(30.5)$ & 11.3 (2.7 to 19.9 ) & $56(47.1)$ & $31(26.3)$ & 20.8 (8.8 to 32.8 ) \\
\hline HTN & $62(36.5)$ & 145 (33.7) & $2.7(-5.8$ to 11.3$)$ & $52(43.7)$ & $37(31.4)$ & 12.3 (0.1 to 24.6 ) \\
\hline CKD & $53(31.2)$ & $92(21.4)$ & $9.8(1.8$ to 17.8$)$ & $33(27.7)$ & $28(23.7)$ & $4(-7.1$ to 15.1$)$ \\
\hline$\geq 1$ vasopressor & $90(52.9)$ & $103(24)$ & 29 (20 to 37.5$)$ & $85(71.4)$ & $71(60.2)$ & $11.3(-0.7$ to 23.3$)$ \\
\hline \multicolumn{7}{|l|}{ Pharmacologic } \\
\hline Remdesivir & $53(31.2)$ & - & - & - & - & - \\
\hline Nitric oxide & $23(13.5)$ & - & - & - & - & - \\
\hline Epoprostenol & $6(3.5)$ & - & - & - & - & - \\
\hline IV corticosteroid & $54(31.2)$ & - & - & - & - & - \\
\hline Paralytic & $67(39.4)$ & - & - & - & - & - \\
\hline Systemic heparin & $68(40)$ & - & - & - & - & - \\
\hline \multicolumn{7}{|l|}{ RRT } \\
\hline CVVHD & $20(11.8)$ & $18(4.2)$ & - & - & - & - \\
\hline iHD & $25(14.7)$ & $19(4.4)$ & - & - & - & - \\
\hline \multicolumn{7}{|c|}{ ICU admits during hospitalization } \\
\hline One & $141(82.9)$ & $365(84.9)$ & - & $93(78.2)$ & $82(69.5)$ & - \\
\hline Two & $23(13.5)$ & $49(11.4)$ & - & $20(16.8)$ & $25(21.2)$ & - \\
\hline Three & $4(2.4)$ & $14(3.3)$ & - & $4(3.4)$ & $9(7.6)$ & - \\
\hline Four & $1(0.6)$ & $2(0.5)$ & - & $1(0.8)$ & $2(1.7)$ & - \\
\hline Six & $1(0.6)$ & $0(0)$ & - & $1(0.8)$ & $0(0)$ & - \\
\hline
\end{tabular}

Note. ${ }^{*}$ Summary values presented as n (\%), or mean \pm standard deviation, or median [25th - 75th percentile]; ${ }^{\text {a If }}>1$, APACHE score was recorded during an ICU admission, the median was used. Abbreviations: MV, mechanical ventilation; CI, confidence interval; OTH, other; UNK, unknown; OR, operating room; ED, emergency department; OSH, outside hospital; ICU, intensive care unit; APACHE, Acute Physiology and Chronic Health Evaluation; BMI, body mass index; DM, diabetes mellitus; HTN, hypertension; CKD, chronic kidney disease; vasopressor, norepinephrine, epinephrine, phenylephrine, vasopressin, angiotensin II infusion; ECMO, extracorporeal membrane oxygenation; IV, intravenous; RRT, renal replacement therapy; CVVHD, continuous venovenous hemodialysis; iHD, intermittent hemodialysis 
Table 2. Clinical outcomes of ICU admissions between 3/22/20 - 5/31/20

\begin{tabular}{|c|c|c|c|c|c|c|}
\hline & $\begin{array}{l}\text { COVID-19 } \\
\text { Admissions } \\
(\mathbf{n}=170)\end{array}$ & $\begin{array}{l}\text { Non-COVID-19 } \\
\text { Admissions } \\
(\mathrm{n}=430)\end{array}$ & $\begin{array}{l}\text { [COVID-19 minus } \\
\text { Non-COVID-19] } \\
\text { Difference (95\% CI) }\end{array}$ & $\begin{array}{l}\text { COVID-19 } \\
\text { Admissions on } \\
\text { MV }(n=119)\end{array}$ & $\begin{array}{l}\text { Non-COVID-19 } \\
\text { Admissions on } \\
\text { MV }(n=118)\end{array}$ & $\begin{array}{l}\text { [COVID-19 on MV minus } \\
\text { Non-COVID-19 on MV] } \\
\text { Difference (95\% CI for } \\
\text { difference) }\end{array}$ \\
\hline ICU LOS, days & $9.3[2.2-18.2]$ & $1.9[0.97-3.8]$ & 7.3 (5.1 to 9.4$)$ & $13.3[8.7-22]$ & $5.1[2.8-11.5]$ & $8.2(5.4$ to 11$)$ \\
\hline Hospital LOS, days & $\begin{array}{l}13.9[6.7-27.7] \\
(\mathrm{n}=170)\end{array}$ & $\begin{array}{l}5.3[2.9-10.3] \\
(\mathrm{n}=428)\end{array}$ & 8.6 (5.6 to 11.6$)$ & $\begin{array}{l}21.1[11.8-35.7] \\
(\mathrm{n}=119)\end{array}$ & $\begin{array}{l}9.9[5.1-21.7] \\
(\mathrm{n}=116)\end{array}$ & $11.2(6.5$ to 15.9$)$ \\
\hline Time on MV, days & - & - & - & $10.3[5.7-16.3]$ & $2.6[1.4-6.1]$ & $7.7(5.4$ to 9.9$)$ \\
\hline Total patient days & 3416 & 4063 & - & 1607 & 1701 & - \\
\hline ICU death & $31(18.2)$ & $31(7.2)$ & $11(4.7$ to 17.3$)$ & $29(24.4)$ & $24(20.3)$ & $4(-6.6$ to 14.6$)$ \\
\hline Hospital death $^{* *}$ & $38(22.4)$ & $41(9.5)$ & 12.8 (6 to 19.7$)$ & $31(26.1)$ & 29 (24.6) & 1.5 (-9.6 to 12.5$)$ \\
\hline \multicolumn{7}{|l|}{ Discharge disposition } \\
\hline Home & $62(36.5)$ & $285(66.6)$ & -30.1 (39 to -21.6$)$ & $31(26.1)$ & $49(42.2)$ & $-16.2(-28$ to -4.2$)$ \\
\hline Other HCF & $2(1.2)$ & $3(0.7)$ & $0.5(-1.3$ to 2.3$)$ & $1(0.8)$ & $2(1.7)$ & $-0.9(-3.8$ to 2$)$ \\
\hline Rehab, SNF & $64(37.6)$ & $79(18.5)$ & $19.2(11$ to 27.3$)$ & $54(45.4)$ & $29(25)$ & 20.4 (8.5 to 32.3$)$ \\
\hline Tx ACF & $2(1.2)$ & $3(0.7)$ & $0.5(-1.3$ to 2.3$)$ & $1(0.8)$ & $1(0.9)$ & $0(-2.4$ to 2.3$)$ \\
\hline AMA & $0(0)$ & $9(2.1)$ & $-2.1(-3.5$ to -0.7$)$ & $0(0)$ & $2(1.7)$ & $-1.7(-4.1$ to 0.6$)$ \\
\hline Hospice & $2(1.2)$ & $8(1.9)$ & $-0.7(-2.8$ to 1.4$)$ & $1(0.8)$ & $4(3.4)$ & $-2.6(-6.3$ to 1.1$)$ \\
\hline Expired & $\begin{array}{l}38(22.4) \\
(\mathrm{n}=170)\end{array}$ & $\begin{array}{l}41(9.6) \\
(\mathrm{n}=428)\end{array}$ & $12.8(5.9$ to 19.6$)$ & $\begin{array}{l}31(26.1) \\
(\mathrm{n}=119)\end{array}$ & $\begin{array}{l}29(25) \\
(\mathrm{n}=116)\end{array}$ & $1.1(-10$ to 12.2$)$ \\
\hline $\begin{array}{l}\text { Disposition of death or } \\
\text { hospice }\end{array}$ & $40(23.5)$ & 49 (11.4) & 12.1 (5.1 to 19.2$)$ & $32(26.9)$ & $33(28)$ & $-1.1(-12$ to 10.3$)$ \\
\hline $\begin{array}{l}\text { Predicted ICU LOS } \\
\text { ACUITY2019, days }\end{array}$ & $\begin{array}{l}5.9[3-6.6] \\
(\mathrm{n}=103)\end{array}$ & $\begin{array}{l}2.6[1.8-5.1] \\
(\mathrm{n}=202)\end{array}$ & 3.3 (2.5 to 4.1$)$ & $\begin{array}{l}6.2[5.5-6.8] \\
(\mathrm{n}=73)\end{array}$ & $\begin{array}{l}5.7[4.5-6.4] \\
(\mathrm{n}=64)\end{array}$ & 0.5 (0 to 1$)$ \\
\hline $\begin{array}{l}\text { O/E ICU LOS } \\
\text { ACUITY2019 }\end{array}$ & $\begin{array}{l}1.5[0.8-3.2] \\
(\mathrm{n}=103)\end{array}$ & $\begin{array}{l}0.8[0.5-1.5] \\
(\mathrm{n}=202)\end{array}$ & 0.7 (0.2 to 1.2$)$ & $\begin{array}{l}2.5[1.2-3.7] \\
(\mathrm{n}=73)\end{array}$ & $\begin{array}{l}0.9[0.4-2.2] \\
(\mathrm{n}=64)\end{array}$ & 1.5 (0.7 to 2.2$)$ \\
\hline $\begin{array}{l}\text { O/E Hosp LOS } \\
\text { ACUITY2019 }\end{array}$ & $\begin{array}{l}1.8[1.1-3.3] \\
(\mathrm{n}=103)\end{array}$ & $\begin{array}{l}0.9[0.6-1.7] \\
(\mathrm{n}=199)\end{array}$ & 0.9 (0.4 to 1.4$)$ & $\begin{array}{l}2.4[1.4-4.2] \\
(\mathrm{n}=73)\end{array}$ & $\begin{array}{l}1.1[0.6-2.4] \\
(\mathrm{n}=61)\end{array}$ & $1.3(0.5$ to 2.0$)$ \\
\hline $\begin{array}{l}\text { Predicted Hospital } \\
\text { Mortality } \\
\text { ACUITY2019,\% }\end{array}$ & $\begin{array}{l}28[5-58] \\
(\mathrm{n}=103)\end{array}$ & $\begin{array}{l}5[2-15] \\
(n=200)\end{array}$ & 23 (10.2 to 35.8$)$ & $\begin{array}{l}50[23-65] \\
(\mathrm{n}=73)\end{array}$ & $\begin{array}{l}21[8.5-50] \\
(\mathrm{n}=62)\end{array}$ & 27 (13.2 to 40.8$)$ \\
\hline $\begin{array}{l}\text { O/E Hospital Mortality } \\
\text { ACUITY2019 }\end{array}$ & $\begin{array}{l}0.8 \\
(\mathrm{n}=103)\end{array}$ & $\begin{array}{l}1.9 \\
(\mathrm{n}=200)\end{array}$ & - & $\begin{array}{l}0.52 \\
(\mathrm{n}=73)\end{array}$ & $\begin{array}{l}1.17 \\
(\mathrm{n}=62)\end{array}$ & - \\
\hline
\end{tabular}

Note. "Summary values presented as $n(\%)$, or mean \pm standard deviation, or median [25th - 75th percentile]; ${ }^{* *}$ Hospital death includes ICU death. Abbreviations: ICU, intensive care unit; LOS, length of stay; MV, mechanical ventilation; HCF, health care facility; SNF, skilled nursing facility; ACF, acute care facility; AMA, against medical advice; O/E, observed/expected

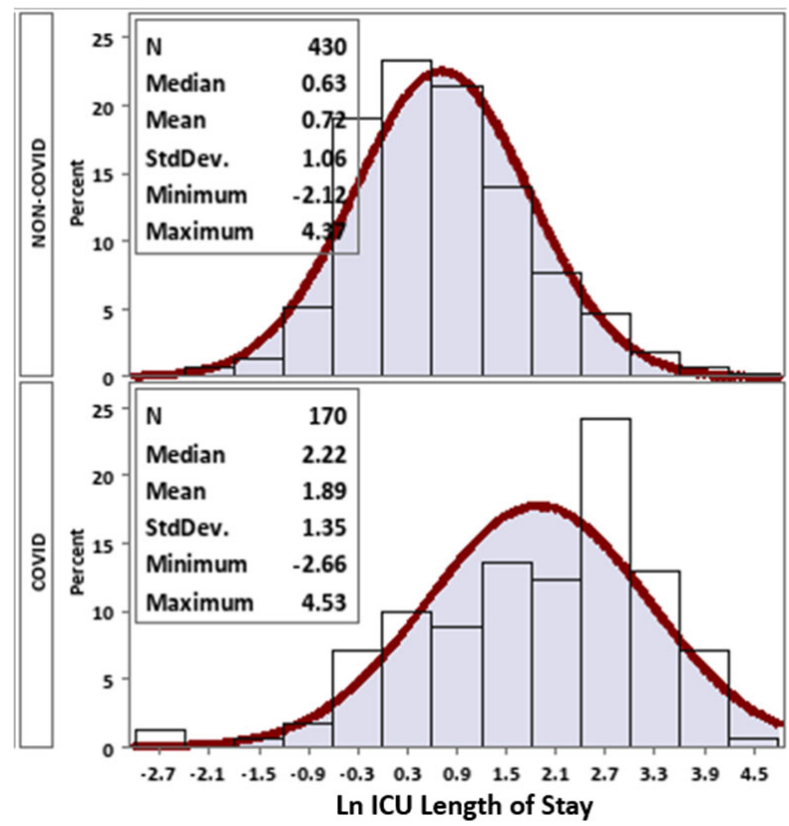

Figure 1. Distribution of ICU LOS in COVID-19 admissions versus non-COVID-19 admissions
Crude hospital and ICU mortality rates were significantly greater in the COVID-19 group (22.4\% vs. $9.5 \% ; 18.2 \%$ vs. $7.2 \%$, respectively). However, there was not a significant ICU mortality difference between patients on MV with and without COVID-19. This finding may be related to the pre-pandemic decanting strategy to admit only the most critically ill non-COVID-19 patients. Hospital and ICU LOS were significantly longer for the COVID-19 cohort (13.9 vs. 5.3 ; 9.3 vs. 1.9 days, respectively). Mortality in admissions with COVID-19 was lower than predicted (O/E: 0.8); whereas, LOS was higher than predicted (O/E: 1.5) based on ACUITY2019. Distributions for LOS are depicted in Figure 1

Table 3 compares the OR for unadjusted versus adjusted hospital mortality in admissions with COVID-19. After adjusting for clinical characteristics, severity of illness, comorbidities, MV, and vasopressor use, SARS-CoV-2 positive status did not confer a higher mortality than those who were non-COVID-19. This is a new finding; comorbidities and severity of illness being equal, SARS-CoV-2 infection did 
not additionally contribute to a higher mortality in our most

comorbidities in determining susceptibility to this disease. critically ill patients. This may highlight the importance of

Table 3. Unadjusted and adjusted odds ratio for COVID-19 as a predictor of hospital death

\begin{tabular}{lll}
\hline Population & $\begin{array}{l}\text { OR for outcome of hospital mortality } \\
\text { (95\% CI) }\end{array}$ & $\boldsymbol{p}$-value \\
\hline 600 ICU admissions (79 deaths) & & \\
COVID-19, unadjusted & $2.73(1.68$ to 4.43$)$ & $<.0001$ \\
COVID-19, adjusted for covariates* & $1.24(0.69$ to 2.24$)$ & .4779 \\
309 ICU admissions and $\geq 1$ APACHE (II/IV) score (53 deaths) & & .0102 \\
COVID-19, unadjusted & $2.20(1.21$ to 4.01$)$ & .7080 \\
COVID-19, adjusted for median APACHE II & $1.14(0.57$ to 2.28$)$ & .8241 \\
COVID-19, adjusted for median APACHE II and covariates* & $1.09(0.50$ to 2.41$)$ & \\
\hline
\end{tabular}

Note. ${ }^{*}$ Covariates include: body mass index $>30 \mathrm{mg} / \mathrm{m}^{2}$, diabetes mellitus, chronic kidney disease, hypertension, mechanical ventilation, vasopressor use, age, gender, and race. Abbreviations: OR, odds ratio; CI, confidence interval; APACHE, Acute Physiology and Chronic Health Evaluation

Hospital and ICU mortality rates were significantly lower than previous reports. ${ }^{[3-13]}$ Mortality data from other studies were derived using completed outcomes, i.e. dead or discharged, as described in each manuscript; incomplete or unknown outcomes were excluded since in many publications patients that were still in the hospital were reported as "surviving", a method that could distort final results. Figure 2a,b compares published mortality data between hospitals and networks.

\section{DisCUSSION}

To our knowledge, this investigation is the first direct comparison of critically ill admissions with and without COVID-19 admitted to an ICU during the height of the pandemic. We found a significant difference in ICU mortality between patients with and without COVID-19 (18.2\% vs 7.2\%, 95\% CI 4.7\%-17.3\%). Importantly, when adjusted for several variables, including body mass index, severity of illness, comorbidities, MV, vasopressor use, age, gender, and race, there was not a significant hospital mortality difference between cohorts. In critically ill patients requiring the most complex care, COVID-19 was not associated with increased mortality when adjusted for comorbidities.

\subsection{Patient characteristics, severity of illness, and re- source utilization}

COVID-19 patients were more frequently admitted to the ICU via transfers from OSH than non-COVID-19 patients. This difference may reflect that smaller hospitals were more likely to transfer COVID-19 patients to a larger, tertiary care facility with more critical care resources, particularly as community hospitals began to overflow during the surge. ICU admission criteria during the pandemic were no different for COVID-19 and non-COVID-19 admissions including emergent medical and surgical cases, life-threatening illness, hemodynamic instability, and acute respiratory failure.

The COVID-19 cohort had similar characteristics to prior studies; men aged 60-70 years with hypertension, diabetes mellitus, and chronic kidney disease.$^{[3-7,10,11]}$ Hispanic patients were more prevalent in the critically ill COVID-19 cohort than in the non-COVID-19 cohort and both Black and Hispanic patients were more prevalent among those requiring MV compared to the non-COVID-19 cohort, consistent with prior studies conducted in large urban centers. ${ }^{[4-7]}$

COVID-19 admissions had higher median APACHE II and IV scores than the non-COVID-19 cohort (23 vs. 15 and 82.5 vs. 50, respectively). In the subset of admissions requiring $\mathrm{MV}$, we found no significant difference in severity of illness among those with and without COVID-19. This finding is consistent with the hospital policy to decant the hospital and discontinue elective surgeries in preparation for an influx of patients with COVID-19 in early March of 2020. As a result, much of the non-COVID-19 cohort was extremely ill and consisted largely of patients requiring emergency, cancer, or transplant medical/surgical care.

COVID-19 admissions required more artificial life supports, including MV, RRT, and vasopressors. The rate of MV in critically ill COVID-19 patients across published studies varied from 63\%-88\% without any apparent temporal relationship. ${ }^{[3-7,11,12]}$ Use of invasive MV likely depended on resource allocation and ICU admission criteria unique to each medical facility making it difficult to compare amongst studies. COVID-19 admissions received more proning, ${ }^{[6,12]}$ but required less vasopressors, ${ }^{[6,7,12]}$ and roughly similar amounts of neuromuscular blockade, ${ }^{[6,12]}$ pulmonary vasodilators, ${ }^{[7,12]}$ and $\mathrm{ECMO}^{[6,7,10,12]}$ compared to other COVID-19 populations.

Notably, we proned 50.6\% of all COVID-19 ICU admissions 
(18 hours continuously prone, 6 hours continuously supine by protocol). A 2013 randomized controlled trial of proning for severe acute respiratory distress syndrome showed a 28- and 90-day mortality benefit for patients who underwent prolonged proning sessions, and more recent prospective studies have confirmed similar improvements in survival. ${ }^{[18,19]}$ The high rate of proning may have contributed to the low mortality rates and avoided unnecessarily escalation to ECMO. Proning has thus far been sparsely reported in the COVID-19 literature. ${ }^{[6,12,20]}$ The complicated logistics and care provider choreography required to avoid catheter and endotracheal tube dislodgements may be responsible for low rates of use, although thus far complication rates reported have been low. ${ }^{[20,21]}$

a.
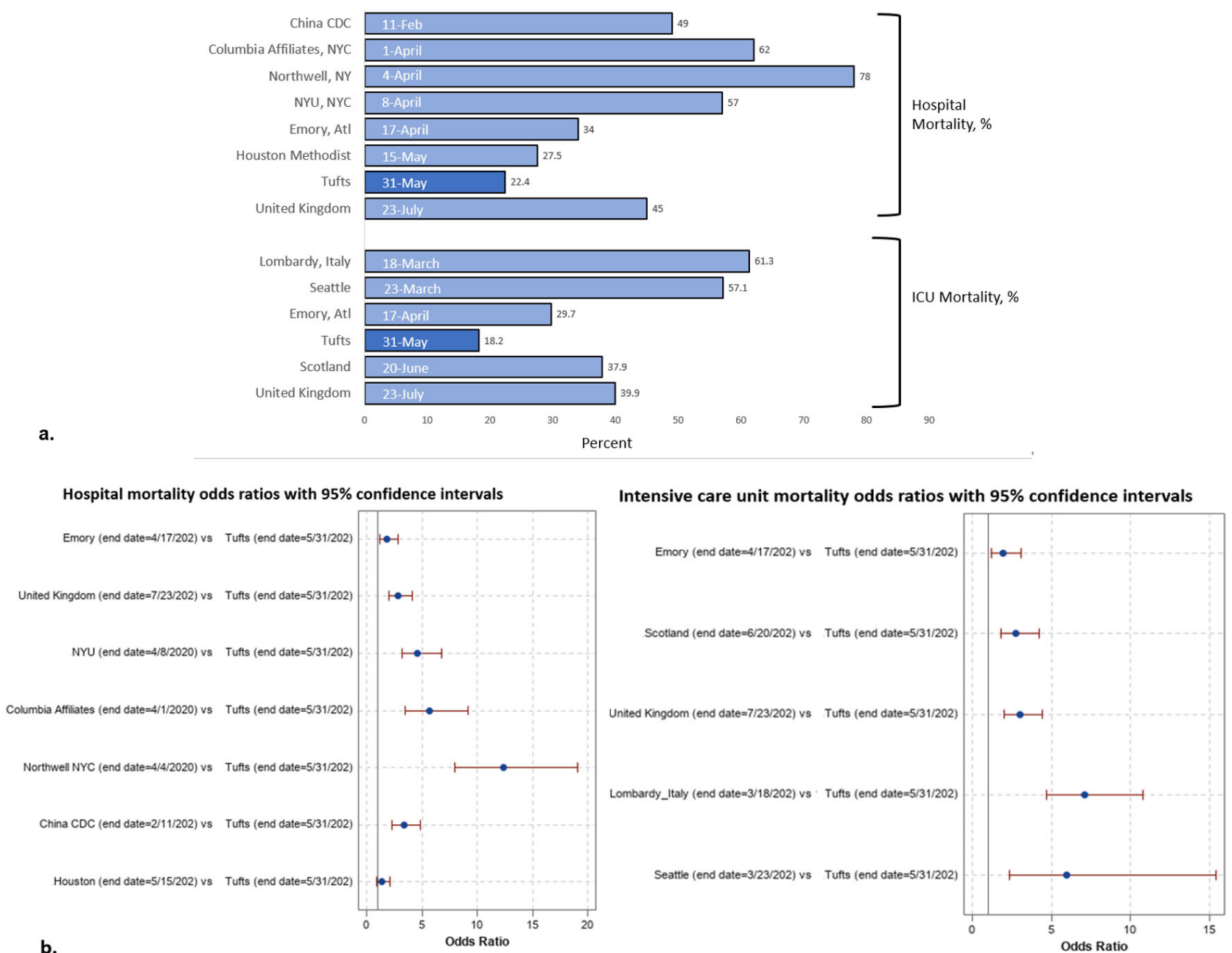

Figure 2. Mortality rates and odds ratios of Tufts Medical Center (TMC) compared to other hospitals for patients with known outcomes

China Center for Disease Control (2,087) (9); Columbia Affiliates, NYC ( $n=163)(6) ;$ Northwell, NY $(n=373)(4)$; New York University, NYC ( $n=990)$ (5); Emory, Atlanta ( $n=209$ [ICU], 197 [hospital]) (7); Houston Methodist ( $n=295)$ (10); TMC, Boston ( $n=198) ;$ United Kingdom ( $n=10,228$ [ICU], 9711 [hospital]) (8); Lombardy, Italy $(n=661)(1) ;$ Seattle, WA $(n=21)(12)$ Scotland ( $n=509)$ (11); Hospital mortality (top); ICU mortality (bottom) calculated from deaths/known study outcomes, i.e. dead or discharged, compared to TMC data. The 95\% CI takes into account both the sample size of TMC and the sample size of the comparison hospital.

Unsurprisingly, the absolute and predicted hospital and ICU LOS were significantly longer for COVID-19 admissions, illustrating the resource-intensive nature of these patients (see Figure 1). The COVID-19 cohort was $28.3 \%$ of the study population yet consumed more than half of all ICU days. COVID-19 admissions required increased multi-disciplinary involvement, escalated clinician and nurse staffing, and more frequent discharge to rehabilitation facilities. Unexpectedly, the rate of readmission was lower in patients with COVID19 perhaps owing to their glacially slow rate of recovery, concordant conservative management, and the high rate of transfer to rehabilitation facilities rather than home. 


\subsection{Patient outcomes on and off the ventilator}

Hospital and ICU mortality rates for COVID-19 admissions were lower compared to those previously published (see Figure $2 \mathrm{a}$ and $2 \mathrm{~b}) \cdot{ }^{[3-12]}$ Armstrong and colleagues recently published the first systematic review and meta-analysis of COVID-19 critically ill patients that included data from 24 studies and 10,150 subjects. The collective ICU mortality rate was $41.6 \%$, which stands in contrast to the rate of $18.2 \%$ in the present study. Armstrong et al postulated that this high mortality in their systematic review could be attributable to the disease process itself, or to the difficulty in providing comprehensive services in a pandemic setting. ${ }^{[22]}$ Not all studies provided hospital or ICU mortality for patients on $\mathrm{MV}$; this information was available in later studies when more patient outcomes were realized (i.e. died versus discharged). Smaller hospital-wide or hospital system-wide studies were more likely to provide this information than larger country-wide studies due to cohesive electronic medical record systems facilitating data collection.

It is noted that the non-COVID-19 group had an O/E mortality ratio of $>1$, which may reflect that our non-COVID-19 admissions were more critically ill than the ICU norm. Alternatively, their severity of illness may not have been accurately captured with the ACUITY2019 software, as a predicted mortality of 5\% is remarkably low for any critically ill cohort. Mortality comparison between critically ill non-COVID-19 patients before and during the study period could elucidate if the non-COVID-19 cohort captured in the study timeframe were managed differently than those before the pandemic.

There are several possible explanations for the low mortality rates observed in the present study. This hospital benefitted from the early experiences in China, Italy, and New York City; greater time for preparation; and a moderate rate of daily admissions. As more COVID-19 mortality data became available during this time frame, a temporal relationship appeared to emerge with reports of decreasing hospital mortality trends with passing months, ${ }^{[6,7,10]}$ although this was not universally evident (see Figure 2a). ${ }^{[8,22]}$ Declining mortality may be attributed to rapid adaptation and implementation of lessons learned as successful clinical strategies disseminate through published literature, formal guidelines, blogs, and social media. ${ }^{[23,24]}$ Some of these successful strategies included lung protective ventilation, early and aggressive proning, and liberal use of corticosteroids. ${ }^{[25-27]}$ Ultimately, the importance of early preparation to attain low mortality rates cannot be overemphasized as the pandemic continues, or new surges emerge.

\subsection{Limitations}

The retrospective and observational nature of the study are limitations. Also, our analysis may lack generalizability as it

Published by Sciedu Press was performed at a single center. It may have been prone to confounding variables, i.e. differing ICU admission criteria, thresholds for MV, or discharge criteria between the COVID19 and non-COVID-19 cohorts, and among other institutions. Unique ICU admissions were used as the study denominator as it was felt to most accurately reflect the disease burden throughout the study period, but this assumption may be suboptimal as we learn more about the natural history of SARS-CoV-2. Furthermore, data were collected using MDN Phoenix Database which relies on accurate coding of patient characteristics, resource utilization, and mortality.

\subsection{Future directions}

As the pandemic unfolds, the body of COVID-19 related literature has evolved rapidly. From single center descriptive reports of the first COVID-19 patients $^{[4-7]}$ to randomized controlled trials evaluating vaccine safety and efficacy, ${ }^{[28-30]}$ the body of scientific research and innovation has made widespread vaccination rollout possible. However, the effects of the COVID-19 pandemic will continue to be felt long after the population is vaccinated. Further research exploring hospital wide policy changes for long term pandemic control, ${ }^{[31]}$ evolving nursing management strategies, ${ }^{[32]}$ effective vaccine distribution, ${ }^{[33]}$ and preventing provider burnout during the pandemic ${ }^{[34]}$ has begun at this hospital and should continue to be widely pursued.

\section{Conclusions}

Critically ill admissions with COVID-19 had greater severity of illness, required more MV, and suffered higher mortality rates compared to the non-COVID-19 cohort during the peak of the pandemic in Boston, MA. Subgroup analysis of patients on MV showed no difference in mortality, indicating that the non-COVID-19 MV patients were even more seriously ill than the ICU norm. Importantly, there was not a significant adjusted OR for COVID-19 as a predictor of hospital death between admissions with and without COVID-19. Comorbidities and severity of illness being equal, SARSCoV-2 infection did not contribute to a higher mortality in our most critically ill patients, a discovery that may be the most important finding of this study. The considerably lower mortality rate among ICU patients at this hospital may be attributable to the "learning curve" from other hospital experiences, early hospital-wide preparation, and persistent, dedicated intensive care. We feel timing and preparation were key to better outcomes realized at our medical center.

\section{ACKNOWLEDGeMENTS}

Timothy Weren, PharmD and Robin Ruthazer, MPH.

\section{CONFlicts OF INTEREST Disclosure}

The authors declare they have no conflicts of interest. 


\section{REFERENCES}

[1] Cutler DM, Summers LH. The COVID-19 Pandemic and the $\$ 16$ Trillion Virus. JAMA 2020; 324(15): 1495-96. PMid: 33044484 https://doi.org/10.1001/jama.2020.19759

[2] Woolf SH, Chapman DA, Sabo RT, et al. Excess Deaths From COVID-19 and Other Causes, March-April 2020. JAMA. 2020; 324(5): 510-13. PMid: 32609307. https://doi.org/10.1001/ jama. 2020.11787

[3] Grasselli G, Zangrillo A, Zanella A, et al. Baseline Characteristics and Outcomes of 1591 Patients Infected With SARS-CoV-2 Admitted to ICUs of the Lombardy Region, Italy. JAMA. 2020; 323(16) 1574-81. PMid: 32250385. https://doi.org/10.1001/jama. 2 020.5394

[4] Richardson S, Hirsch JS, Narasimhan M, et al. Presenting Characteristics, Comorbidities, and Outcomes Among 5700 Patients Hospitalized With COVID-19 in the New York City Area. JAMA. 2020; 323(20): 2052-59. PMid: 32320003. https ://doi .org/10.100 1/jama.2020.6775

[5] Petrilli CM, Jones SA, Yang J, et al. Factors associated with hospital admission and critical illness among 5279 people with coronavirus disease 2019 in New York City: prospective cohort study. BMJ. 2020; 369: m1966. PMid: 32444366. https ://doi.org/10.1136/bmj . m1966

[6] Cummings MJ, Baldwin MR, Abrams D, et al. Epidemiology, clinical course, and outcomes of critically ill adults with COVID-19 in New York City: a prospective cohort study. Lancet. 2020; 395: 1763-70. https ://doi .org/10.1016/S0140-6736 (20)31189-2

[7] Auld SC, Caridi-Scheible M, Blum JM, et al. ICU and ventilator mortality among critically ill adults with COVID-19. Crit Care Med 2020; 48(9): e799-e804. https://doi.org/10.1101/2020.04 23. 20076737

[8] Intensive Care National Audit and Research Centre. ICNARC report on COVID-19 in critical care 24 July 2020. Accessed 30 July 2020 Available from: https//:www.icnarc.org/Our-Audit/Audit $\mathrm{s} / \mathrm{Cmp} /$ Reports

[9] Wu Z, McGoogan JM. Characteristics of and important lessons from the Coronavirus Disease 2019 (COVID-19) outbreak in China: Summary of a report of 72,314 cases from the Chinese Center for Disease Control and Prevention. JAMA. 2020; 323(13): 1239-42. PMid: 32091533. https://doi.org/10.1001/jama.2020.2648

[10] Vahidy FS, Drews AL, Masud FN, et al. Characteristics and outcomes of COVID-19 patients during initial peak and resurgence in the Houston metropolitan area. JAMA. 2020; 324(10): 998-1000. PMid: 32789492. https://doi.org/10.1001/jama.2020.15301

[11] Scottish Intensive Care Society Audit Group report on COVID-19. 20 June 2020 [Accessed September 9, 2020]. Available from https://beta.isdscotland.org/find-publications-and -data/population-health/covid-19/scottish-intensi ve-care-society-audit-group-report-on-covid-19/

[12] Bhatraju PK, Ghassemieh BJ, Nichols M, et al. Covid-19 in Critically Ill Patients in the Seattle Region - Case Series. N Engl J Med. 2020; 382(21): 2012-2022. PMid: 32227758. https://doi.org/10.1 056/NEJMoa2004500

[13] Bilinski A, Emanuel EJ. COVID-19 and excess all-cause mortality in the US and 18 comparison countries. JAMA. 2020. PMid: 33044514 https://doi.org/10.1001/jama.2020.20717

[14] Tian T, Bugaev N, Johnson B, el al. Novel tracheostomy and percutaneous endoscopic gastrostomy technique for COVID-19 patients in a non-negative pressure environment. Am Surg. 2020. In press. PMid: 33284040. https : //doi.org/10.1177/0003134820960072

[15] Stephens JR, Stümple R, Patel P, et al. Analysis of Critical Care Severity of Illness Scoring Systems in Patients with Coronavirus
Disease 2019: A Retrospective Analysis of Three U.K. ICUs. To the Editor. Crit Care Med. 2020. PMid: 32991357. https : //doi.org/ 10.1097/CCM. 0000000000004674

[16] Knaus WA, Draper EA, Wagner D, et al. APACHE II: A severity of disease classification system. Crit Care Med. 1985; 13: 818-829. PMid: 3928249. https ://doi.org/10.1097/00003246-19851 0000-00009

[17] Zimmerman JE, Kramer AA, McNair DS, et al. Acute Physiology and Chronic Health Evaluation (APACHE) IV: hospital mortality assessment for today's critically ill patients. Crit Care Med. 2006; 34(5): 1297-1310. PMid: 16540951. https://doi.org/10.109 7/01.CCM.0000215112.84523.F0

[18] Guerin C, Reignier J, Richard JC, et al. Prone Positioning in Severe Acute Respiratory Distress Syndrome. N Engl J Med. 2013; 368: 2159-68. PMid: 23688302. https : //doi .org/10.1056/NEJMoa 1214103

[19] Guérin C, Beuret P, Constantin JM, et al. A prospective international observational prevalence study on prone positioning of ARDS patients: the APRONET (Ards prone position network) study. Intensive Care Med. 2018; 44(1): 22-37. PMid: 29218379. https ://doi.org/10.1007/s00134-017-4996-5

[20] Telias I, Katira BH, Brochard L. Is the prone position helpful during spontaneous breathing in patients with covid-19? JAMA. 2020; 323(22): 2265. PMid: 32412579. https ://doi.org/10.1001/ja ma. 2020.8539

[21] Lucchini A, Bambi S, Mattiussi E, et al. Prone position in acute respiratory distress syndrome patients: a retrospective analysis of complications. Dimens Crit Care Nurs. 2020; 39(1): 39-46. PMid: 31789984. https://doi.org/10.1097/DCC.00000000000003 93

[22] Armstrong RA, Kane AD, Cook TM. Outcomes from intensive care in patients with COVID-19: a systematic review and meta-analysis of observational studies. Anaesthesia. 2020; 75(10): 1340-49. PMid: 32602561. https://doi.org/10.1111/anae.15201

[23] Doige FC, Mouncey PR, Thomas K, et al. Trends in intensive care for patients with COVID-19 in England, Wales and Northern Ireland. Preprints. 2020. In press. PMid: 33306946. https: //doi.org/10.1164/rccm. 202008-32120C

[24] Horowitz LI, Jones SA, Cerfolio RJ, et al. Trends in COVID-19 Risk Adjusted Mortality Rates. Journal of Hospital Medicine. 2020. In press. https://doi.org/10.1101/2020.08.11.20172775

[25] Villar J, Ferrando C, Martínez D, et al. Dexamethasone treatment for the acute respiratory distress syndrome: a multicentre, randomised controlled trial. The Lancet Respiratory Medicine. 2020; 8(3): 267 276. https://doi .org/10.1016/S2213-2600(19)30417-5

[26] The WHO Rapid Evidence Appraisal for COVID-19 Therapies (REACT) Working Group, Sterne JAC, Murthy S, et al. Association between administration of systemic corticosteroids and mortality among critically ill patients with covid-19: a meta-analysis. JAMA 2020; 324(13): 1330.

[27] The RECOVERY Collaborative Group. Dexamethasone in hospitalized patients with covid-19 - preliminary report. N Engl J Med Published online July 17, 2020: NEJMoa2021436.

[28] Voysey M, Clemens S, Madhi S, et al. Safety and efficacy of the ChAdOx1 nCoV-19 vaccine (AZD1222) against SARS-CoV2: an interim analysis of four randomized controlled trials in Brazil, South Africa, and the UK. The Lancet. 2021; 397(10269): 99-111. https ://doi .org/10.1016/S0140-6736(20)32661-1

[29] Polack F, Thomas S, Kitchin N, et al. Safety and efficacy of the BNT162b2 mRNA Covid-19 Vaccine. N Engl J Med. 2020; 383(27): 2603-2615. PMid: 33301246. https ://doi.org/10.1056/NEJM oa2034577 
[30] Baden L, Sahly H, Essink B, et al. Efficacy and safety of the mRNA1273 SARS-CoV-2 vaccine. N Engl J Med. 2021; 384(5): 403-416. PMid: 33378609. https ://doi.org/10.1056/NEJMoa2035389

[31] Charpentier A, Elie R, Lauriere M, et al. COVID-19 pandemic control: balancing detection policy and lockdown intervention under ICU sustainability. Math Model Nat Phenom. 2020; 15: 57. https://doi.org/10.1051/mmp/2020045

[32] Bambi S, Iozzo P, Lucchini A. New issues in nursing management during the COVID-19 pandemic in Italy. Am J Crit Care. 2020; 29(4):
92-93. PMid: 32467964. https ://doi .org/10.4037/ajcc2020 937

[33] Kim J, Marks F, Clemens J. Looking beyond COVID-19 vaccine phase 3 trials. Nature Medicine. 2021; 27(2021): 205-211. PMid: 33469205. https://doi.org/10.1038/s41591-021-01230-y

[34] Kok N, Van Gurp J, Teerenstra S, et al. Coronavirus disease 2019 immediately increased burnout symptoms in ICU professionals: a longitudinal cohort study. Critical Care Medicin. 2021; 49(3): 419427. PMid: 33555778. https ://doi .org/10.1097/CCM. 000000 0000004865 